\title{
Hypoglycemic effect of Bromelia plumieri (E. Morren) L.B. Sm., leaves in STZ-NA-induced diabetic rats
}

\author{
Adolfo Andrade-Cetto* and Anamarel E. Medina-Hernández \\ Laboratorio de Etnofarmacología, Departamento de Biología Celular, Facultad de Ciencias, Universidad Nacional Autónoma de México, Coyoacán 04510, D.F. \\ México
}

\section{Edited by:}

Thomas Efferth, University of Mainz, Germany

\section{Reviewed by:}

Thomas Efferth, University of Mainz, Germany

Sara Serafina Sanchez, Universidad Nacional de Tucumán, Argentina Mohammad Sarwar Alam, Jamia Hamdard, India

\section{${ }^{*}$ Correspondence:}

Adolfo Andrade-Cetto, Laboratorio de Etnofarmacología, Departamento de Biología Celular, Facultad de Ciencias, Universidad Nacional Autónoma de México, Apartado Postal 70-359, Coyoacan 04510, Mexico City, Mexico.

e-mail:aac@.ciencias.unam.mx
This study confirms the hypoglycemic effects of two extracts obtained from the Bromelia plumieri (BP) plant in streptozotocin-nicotinamide-induced diabetic rats (STZ-NA). BP has been traditionally used in the municipality of Tlanchinol Hidalgo, Mexico, to treat type 2 diabetes. Two different BP extracts were prepared and tested. The first extract was a water extract (WE), similar to that traditionally used to make tea, and the second extract was an ethanol:water extract (EWE). The extracts (WE at 35 and $350 \mathrm{mg} / \mathrm{kg}$, and EWE at 30 and $300 \mathrm{mg} / \mathrm{kg}$ ) were tested in STZ-NA-induced diabetic rats to determine whether hypoglycemia occurred after oral administration of the extracts. Phytochemistry: Two different extracts were prepared, $n$-hexane and butanol, to determine the presence of alkaloids, terpenes and flavonoids. The extracts that were administered to the STZ-NAinduced diabetic rats produced a significant hypoglycemic effect as compared with the control group, similar to that achieved with glibenclamide. We also determined that flavonoids were the main components of BP leaves. The results presented here support the hypothesis that extracts obtained from this plant have hypoglycemic effects, which are in agreement with the traditional uses of this plant.

Keywords: Ethnobotany, Ethnopharmacology, Bromelia plumieri, streptozotocin-nicotinamide-induced diabetic rats, type 2 diabetes, traditional medicine

\section{INTRODUCTION}

Diabetes mellitus is defined as hyperglycemia that is associated with inadequate insulin secretion, either in the presence or absence of impaired insulin action. Type 2 diabetes (T2D) is characterized by tissue insulin resistance combined with a relative deficiency in insulin secretion. An individual may present primarily with either insulin resistance or $\beta$ cell deficiencies, and these abnormalities can range from mild to severe. The longterm complications of diabetes include: retinopathy with potential loss of vision, nephropathy leading to renal failure, peripheral neuropathy with risk of foot ulcers and amputation, and autonomic neuropathy that can cause gastrointestinal, genitourinary, and cardiovascular symptoms and sexual dysfunction (Expert Committee on the Diagnosis and Classification of Diabetes Mellitus, 2003).

Type 2 diabetes is a public health problem. According to the (World Health Organization [WHO], 2013), more than 347 million patients are affected by this disease worldwide. In 2010, the WHO acknowledged that this disease is a major cause of mortality in Mexico. In the 2008 Mexican health services report, diabetes was found to be the first-highest cause of mortality in Mexico (SINAIS, 2013).

Diabetic people in Mexico commonly use medicinal plants to treat T2D, with or without the concomitant use of medically prescribed hypoglycemic agents (Andrade-Cetto and Heinrich, 2005). We found that in the municipalities of Tlanchinol and Tepehuacan de Guerrero in the Mexican state of Hidalgo, the leaves of the Bromelia plumieri (BP) plant are used to treat T2D.

\section{PLANT BACKGROUND}

Bromelia plumieri (E. Morren) L. B. Sm. Bromeliaceae, also known as B. karatas L. and Karatas plumieri E. Morren, is often referred to in Mexico by the traditional names chichipo, chiyol (Espejo-Serna et al., 2005), piñuela, aguama, and cazuela (SIIT, 2013).

Bromelia plumieri is a tropical herb that is distributed between 400 and $1500 \mathrm{~m}$ in elevation. The leaves are elongated, thick and contain sharp teeth along the margins. Inflorescence sessile at the ground level. Flowering of the plant occurs between May and October (Espejo-Serna et al., 2005). The fruits of the plant range from 5 to $10 \mathrm{~cm}$ long and 1 to $2 \mathrm{~cm}$ in diameter and have a brown epidermis that is covered by a thin ocher colored layer (Parada and Duque, 1998).

The aim of the current study was to examine the acute hypoglycemic effects of BP leaf extracts that were made with either water or a mixture of ethanol and water in streptozotocin-nicotinamide (STZ-NA)-induced diabetic rats. We also sought to characterize the main components of the plant.

\section{MATERIALS AND METHODS ETHNOBOTANY}

Direct interviews regarding plant use were conducted with a plant expert from Tlanchinol, Hidalgo, named Isabel Escalante, who reported that the plant grows in San Simon, Hidalgo. This information was confirmed by the inhabitants of the location, and samples were collected in situ. The identity of the samples was confirmed, by the specialist "Ramiro Cruz Duran." Seven Kilograms of BP leaves were collected from different locations, 
after which point the plant material was dried under constant conditions at $40^{\circ} \mathrm{C}$, ground in an IKA Mf10 mill and stored at room temperature.

\section{PLANT EXTRACTS}

Plant extracts were prepared to both, study their hypoglycemic effects and to investigate the basic phytochemical composition of the plant. The water extract (WE), similar to that traditionally used to make tea, was made by boiling $27.3 \mathrm{~g}$ of the dry plant material in $500 \mathrm{ml}$ of water, followed by filtration and lyophilization. The ethanol-water extract (EWE) was prepared by adding $20 \mathrm{~g}$ of the plant material to $800 \mathrm{ml}$ of an ethanol and water mixture (50:50). The extract was then heated at $40^{\circ} \mathrm{C}$ for $4 \mathrm{~h}$; thereafter it was filtered three times, followed by evaporation in a Büchi rotary evaporator.

Phytochemical analysis of the plant was performed by extracting $60 \mathrm{~g}$ using a Soxhlet extractor with $n$-hexane (HE) followed by methanol. The dry methanol extract was partitioned with butanol and water at a 1:1 ratio, and the butanolic phase was then dried (BE), followed by evaporation of all of the extracts in a rotary Büchi evaporator. All of the extracts were kept at $-4^{\circ} \mathrm{C}$ until use.

\section{TLC ANALYSIS}

The water, EWE, HE, and BE extracts were analyzed using standard TLC methods. Briefly, the samples were applied to a Merck $10 \mathrm{~mm} \times 10 \mathrm{~mm} 60 \mathrm{~F} 254$ plate containing tree solvent systems. For alkaloids, a mixture containing dichloromethane, 85: $\mathrm{MeOH}$, 14: $\mathrm{NH}_{4} \mathrm{OH}(25 \%), 1$, was used and the plate was visualized using Dragendorff's reagent. For glycated flavonoids, a mixture containing ethyl acetate, 60: formic acid, 10: acetic acid, 10: water, 20 was used. For aglycone flavonoids, a $50 \mathrm{ml}$ mixture containing chloroform, 35: acetone, 10 and formic acid 5, was used. Both plates were visualized using diphenylborinic acid. For terpenes, a $20 \mathrm{ml}$ mixture containing ethyl acetate, 6 : HE 14, was used. The plate was visualized using vanillin (Wagner and Bladt, 2001; Andrade-Cetto and Rubalcaba-Mares, 2012).

\section{ANIMALS AND INDUCTION OF EXPERIMENTAL DIABETES}

Eight-week-old Wistar rats weighing 200-250 g were obtained from either the Bioterium of the School of Science or the Bioterium of the Physiological Institute (UNAM) and were acclimatized with free access to food and water for at least 1 week in an air conditioned room $\left(25^{\circ} \mathrm{C}\right.$ and $55 \%$ humidity) with a $12 \mathrm{~h}$ light-dark cycle prior to performing the experiments. All methods used in this study were approved by the Internal Council of the Facultad de Ciencias of the Universidad Nacional Autónoma de México. Experimental diabetes was induced as described by Masiello et al. (1998). Rats that had fasted overnight were injected intraperitoneally with $230 \mathrm{mg} / \mathrm{kg}$ nicotinamide (NA; Sigma, N3376) $15 \mathrm{~min}$ prior to an intravenous injection of $65 \mathrm{mg} / \mathrm{kg}$ streptozotocin (STZ) in citrate buffer (Sigma, S0130).

\section{BLOOD COLLECTION AND BLOOD GLUCOSE DETERMINATIONS}

Animals were handled according to the National Institutes of Health Guide for the Care and Use of Laboratory Animals (Committee for the Update of the Guide for the Care and Use of Laboratory Animals, 2011). Plasma glucose concentrations were measured using an Accutrend GC and were confirmed with a Reflotron instrument (Roche). Each assay was performed in duplicate. In total, $32 \mu \mathrm{l}$ of blood was used in each assay.

\section{EXPERIMENTAL GROUPS}

The animals were divided into seven different groups (1-7). Each group contained 11 rats. Group 1 was the non-diabetic control group. Group 2, the diabetic control group, both groups received $6 \mathrm{ml} / \mathrm{kg}$ of a normal saline solution. Group 3 was administered $5 \mathrm{mg} / \mathrm{kg}$ of glibenclamide, a standard oral hypoglycemic agent that was dissolved in physiological $\mathrm{NaCl}$ solution. Groups 4 and 5 received WE $(35 \mathrm{mg} / \mathrm{kg}$ and $350 \mathrm{mg} / \mathrm{kg}$, respectively), and groups 6 and 7 received EE $(30 \mathrm{mg} / \mathrm{kg}$ and $350 \mathrm{mg} / \mathrm{kg}$, respectively). The extracts were administrated in a physiological $\mathrm{NaCl}$ solution.

\section{STATISTICAL ANALYSES}

The data were analyzed using one-way ANOVA followed by Bonferroni and Fisher tests. Plasma glucose levels were expressed as the means \pm S.E.M.

\section{RESULTS}

\section{ETHNOBOTANY}

In the studied communities, the plant was referred to by its common names: piñuela or timbiriche. The plant was deposited at the IMSS Herbarium in Mexico City under voucher number IMMSM15814. We confirmed via direct interviews that the leaves of the plant are used to treat T2D. To treat the disease, approximately $30 \mathrm{~g}$ of dry plant material is boiled in $1000 \mathrm{ml}$ of water, which is consumed over the course of the day.

\section{YIELD AND PHYTOCHEMICAL COMPOSITION}

Analysis indicated that the drug was present at a ratio of 8:1 in the WE, 9:1 in the EWE and 164:1 BE (Gaedcke and Steinhoff, 2003). Using TLC, we confirmed that the main compounds found in the plant leaves are glycosylated flavonoids, which were present in both extracts 6 (WE) and 4 (EWE), whereas seven spots were detected in the BE extract Figure 1. Terpenes were also detected in the WE and EWE extracts ( 2 spots), whereas four spots were detected in the HE. We were unable to detect the presence of alkaloids in the extracts (data not shown). In the TLC plates from the WE, EWE, and BE, we observed spots with a yellow-green coloration, which were indicative of glycosylated flavons and flavonols (Wagner and Bladt, 2001).

\section{ACUTE HYPOGLYCEMIC EFFECT}

We confirmed that the administration of NA followed by an injection of STZ to normal rats significantly $(p<0.001)$ elevated blood glucose levels as compared with rats that were injected with citrate buffer alone. These results were similar to those reported by Masiello et al. (1998) (Table 1).

In the diabetic rats, the positive control glibenclamide showed a hypoglycemic effect from 60 through $180 \mathrm{~min}$ as compared to the control group at time 0 . The plant extracts also displayed significant hypoglycemic effects (Table 1). 


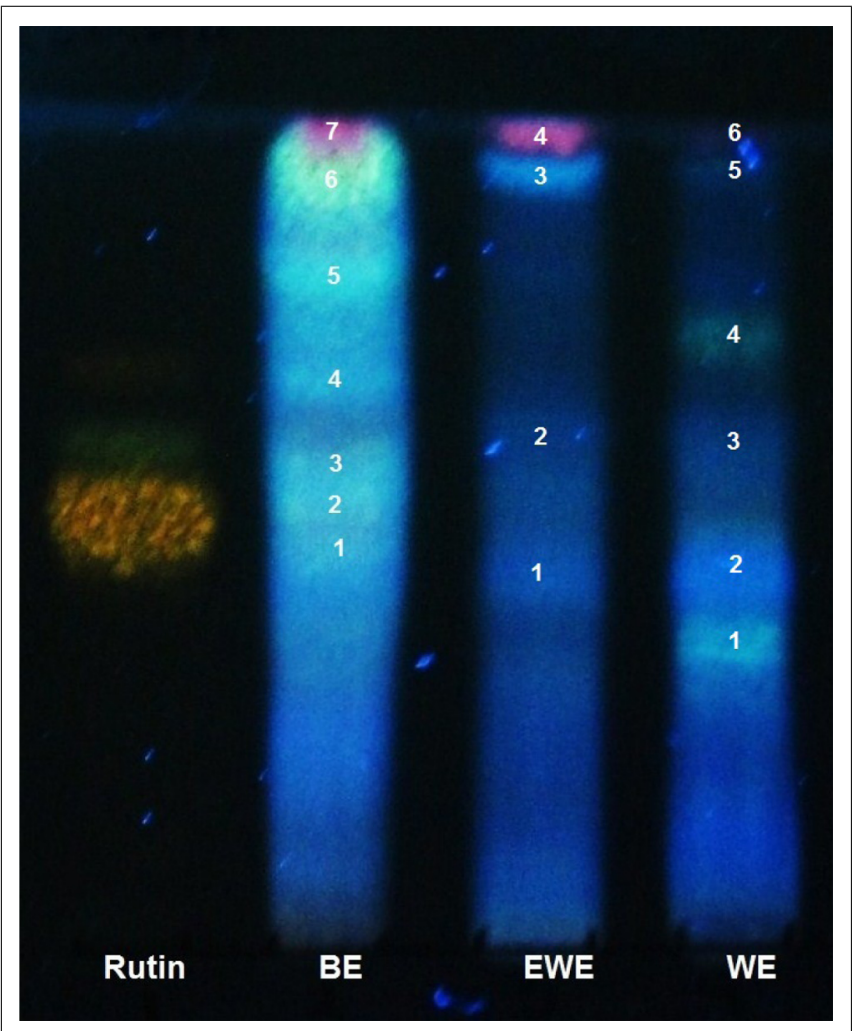

FIGURE 1 | Thin layer Chromatography of Bromelia plumieri leaves; $B E$, butanol extract, EWE, ethanol:water extract; WE, water extract. Plates were visualized using diphenylborinic acid; the numbers indicate the detected compound

Rats orally treated with a $35 \mathrm{mg} / \mathrm{kg}$ dose of the WE demonstrated hypoglycemia after 120 min which remained significant until $180 \mathrm{~min}$ as compared with the time 0 . At the $350 \mathrm{mg} / \mathrm{kg}$ dose, the rats that had been treated with the WE had hypoglycemia from 60 to $180 \mathrm{~min}$ compared with the control group and time 0 . The WE exerts an early hypoglycemic effect at the $350 \mathrm{mg} / \mathrm{kg}$ dose as compared with the $35 \mathrm{mg} / \mathrm{kg}$ dose. Maximal effects of the WE were observed after $180 \mathrm{~min}$ of treatment (Table 1).

Treatment of the diabetic rats with $30 \mathrm{mg} / \mathrm{kg}$ of the EWE led to significant decreases in plasma glucose levels from the $120 \mathrm{~min}$ time point through the $180 \mathrm{~min}$ time point as compared with the control group. At doses of $300 \mathrm{mg} / \mathrm{kg}$, there was a significant effect from 120 through $180 \mathrm{~min}$ as compared to the with the control group and time 0 . Treatment with $300 \mathrm{mg} / \mathrm{kg}$ doses also produced a robust effect as compared with the $30 \mathrm{mg} / \mathrm{kg}$ treated group. Maximal activity of the ethanol-WE was observed after $180 \mathrm{~min}$.

These results support acceptance of the null hypothesis that there are no significant differences between treatment with the tested plant extracts and glibenclamide, a standard hypoglycemic drug.

\section{DISCUSSION}

In Mexico, people who suffer from T2D often use medicinal plants to treat the disease, with or without concomitant medical
Table 1 | Acute hypoglycemic effects of Bromelia plumieri leaves on STZ-NA-induced diabetic rats.

\begin{tabular}{|c|c|c|c|c|}
\hline $\begin{array}{l}\text { Glucose (mg/dl) } \\
\text { Groups }\end{array}$ & TO & $T 60$ & $T 120$ & $T 180$ \\
\hline 1 ND Control & $115 \pm 3$ & $120 \pm 4$ & $111 \pm 4$ & $107 \pm 3$ \\
\hline $2 D$ Control & $168 \pm 4^{3}$ & $171 \pm 5^{3}$ & $173 \pm 3^{3}$ & $162 \pm 4^{3}$ \\
\hline $\begin{array}{l}3 D+G \\
(5 \mathrm{mg} / \mathrm{kg})\end{array}$ & $167 \pm 4$ & $145 \pm 5^{2, b}$ & $119 \pm 4^{3, c}$ & $110 \pm 3^{3, c}$ \\
\hline $\begin{array}{l}4 D+W E \\
(350 \mathrm{mg} / \mathrm{kg})\end{array}$ & $163 \pm 3$ & $148 \pm 3^{1, b, l}$ & $142 \pm 3^{3, b, \| l}$ & $142 \pm 3^{3, b}$ \\
\hline $\begin{array}{l}5 D+W E \\
(35 \mathrm{mg} / \mathrm{kg})\end{array}$ & $173 \pm 5$ & $170 \pm 9$ & $161 \pm 6^{a}$ & $148 \pm 4^{1, b}$ \\
\hline $\begin{array}{l}6 D+E W E \\
(300 \mathrm{mg} / \mathrm{kg})\end{array}$ & $173 \pm 4$ & $162 \pm 5$ & $155 \pm 4^{2, a}$ & $144 \pm 3^{2, c}$ \\
\hline $\begin{array}{l}7 D+E W E \\
(30 \mathrm{mg} / \mathrm{kg})\end{array}$ & $167 \pm 4$ & $161 \pm 3$ & $156 \pm 3^{1}$ & $147 \pm 4^{1, b}$ \\
\hline
\end{tabular}

The values represent the means \pm SEM. Superscript letters in the same row indicate statistical differences as compared with time 0 . Superscript numbers in the same column indicate statistical differences from the control group (diabetic control group compared with non-diabetic control group). Superscript Roman numerals in the same column indicate statistical differences between the two doses of the same extract. "a, 1,1 " indicates significance at $p<0.05$, "b,2, Il" indicates significance at $p<0.01$, and " $c, 3$ " indicates significance at $p<0.001$. Gl, glucose; ND, non-diabetic; D, diabetic; G, glibenclamide; EWE, Ethanol:water extract; WE, water extract.

intervention (Andrade-Cetto, 2010). This phenomenon reinforces the importance of the study of traditionally used hypoglycemic plants, because not all of the plants used induce the desired effect. In the present study, BP exerted a statistically significant hypoglycemic effect. In the rat model used in the present study, the injection of NA followed by STZ increased glucose levels in rats as compared with the non-diabetic control group. Glibenclamide at $5 \mathrm{mg} / \mathrm{kg}$ decreased these levels, indicating that the STZ-NA model is an adequate model that can be used to test the efficacy of hypoglycemic plants. Treatment with the WE of Bromelia at $350 \mathrm{mg} / \mathrm{kg}$ produced the best hypoglycemic effect. Traditionally, the plant preparation is boiled and the infusion is consumed over the next several hours. In the present study, we found that this dose $(35 \mathrm{mg} / \mathrm{kg})$ reduces glucose levels after $120 \mathrm{~min}$. However, a dose of $350 \mathrm{mg} / \mathrm{kg}$ produced a superior effect. We also found that the main components of the extracts are flavons and flavonols. These compounds are known to produce hypoglycemic effects, as previously demonstrated by Torres-Piedra et al. (2010).

Altogether, the results of the present study demonstrate the hypoglycemic effects of $\mathrm{BP}$ and support the traditional use of the plant for the treatment of T2D.

\section{ACKNOWLEDGMENTS}

We would like to thank to Biol. Ramiro Cruz Duran, for the correct plant determination, to M.V. Z. Mario Soriano-Bautista, Biol. Dora Salazar and Biol. Isabel Antúnez for housing the animals. This work was partially supported by the DGAPA, PAPIIT projects IN228510 and IN214413, and CONACyT CB 079910. 


\section{REFERENCES}

Andrade-Cetto, A. (2010). "Mexican plants traditionally used from the treatment of type 2 diabetes," in Advances in Obesity-Diabetes research at UNAM, eds M. Hiriart and J. Mas Oliva (Mexico: El manual Moderno), 191-200.

Andrade-Cetto, A., and Heinrich, M. (2005). Mexican plants with hypoglycaemic effect used in the treatment of diabetes. J. Ethnopharmacol. 99, 325-248.

Andrade-Cetto, A., and RubalcabaMares, M. L. (2012). Hypoglycemic effect of the Rhizophora Mangle Cortex on STZ-NA induced diabetic rats. Pharmcologyonline 3, $1-5$.

Committee for the Update of the Guide for the Care and Use of Laboratory Animals. (2011). Guide for the Care and Use of Laboratory Animals. Washington, DC: The National Academies Press.

Espejo-Serna, A., López-Ferrari, A. R., and Ramírez-Morillo, I. (2005) "Bromeliaceae," in Flora of Veracruz (Xalapa: Inst Ecología), 103.
Expert Committee on the Diagnosis and Classification of Diabetes Mellitus. (2003). Report of the expert committee on the diagnosis and classification of diabetes mellitus. Diabetes Care 26(Suppl. 1), S5-S20.

Gaedcke, F., and Steinhoff, B. (2003). Expert Committee on the Diagnosis and Classification of Diabetes Mellitus. Herbal Medicinal Products. Stuttgart: Medpharm Scientific.

Masiello, P. C., Broca, R., Gross, M., Roye, M., Manteghetti, D., HillaireBuys, M., etal. (1998). Experimental NIDDM: development of a new model in adult rats administered streptozotocin and nicotinamide. Diabetes 47, 224-229.

Parada, F., and Duque, C. (1998). Studies on the aroma of piñuela fruit pulp (Bromelia plumieri): free and bound volatile composition and characterization of some glucoconjugates as aroma precursors. J. High Resolut. Chromatorgr. 21, 577-581.

SIIT. (2013). Integrated Taxonomic Information System, CONABIO.
Available at: http://siit.conabio. gob.mx (Accessed: January, 2013).

SINAIS. (2013). National Health Information System. Mexican Government. Available at: http://sinais.salud. gob.mx (Accessed: January, 2013).

Torres-Piedra, M., Ortiz-Andrade, R., Villalobos-Molina, R., Singh, N., Medina-Franco, J. L., Webster, S. P., etal. (2010). A comparative study of flavonoid analogues on streptozotocin-nicotinamide induced diabetic rats: quercetin as a potential antidiabetic agent acting via 11beta-hydroxysteroid dehydrogenase type 1 inhibition. Eur. J. Med. Chem. 45, 2606-2612.

Wagner, H., and Bladt, S. (2001). Plant Drug Analysis. A Thin Layer Chromatography Atlas, 2nd Edn. Berlin: Springer- Verlag.

World Health Organization [WHO]. (2013). WHO Fact sheet $\mathrm{N}^{\circ} 312$. Available at: http://www.who.org (Accessed: January, 2013).

Conflict of Interest Statement: The authors declare that the research was conducted in the absence of any commercial or financial relationships that could be construed as a potential conflict of interest.

Received: 05 February 2013; accepted: 16 March 2013; published online: 09 April 2013.

Citation: Andrade-Cetto A and MedinaHernández AE (2013) Hypoglycemic effect of Bromelia plumieri (E. Morren) L.B. Sm. leaves in STZ-NA-induced diabetic rats. Front. Pharmacol. 4:36. doi: 10.3389/fphar.2013.00036

This article was submitted to Frontiers in Ethnopharmacology, a specialty of Frontiers in Pharmacology.

Copyright (c) 2013 Andrade-Cetto and Medina-Hernández. This is an openaccess article distributed under the terms of the Creative Commons Attribution License, which permits use, distribution and reproduction in other forums, provided the original authors and source are credited and subject to any copyright notices concerning any third-party graphics etc. 